\title{
Syntyvyyden säännöstelyn sosiaalisesta ja terveydellisestä taustasta Suomessa
}

\section{Väestöliiton avioliiftoneuvolan kirjeenvaihtoon vv. 1948-1949 perusfuva fułkielma.}

Kirjoittanut Leena Valvanne.

Väestöliitto avasi ensimmäisen avioliittoneuvolansa Helsingissä maaliskuussa 1947. Päätarkoituksena siinä valistustyössä, jota tässä neuvolassa oli aikomuksena suorittaa, oli ryhtyä ehkäisemään rikollisia keskenmenoja, joiden lukumäärä nimenomaan aviovaimojen kohdalla oli kohonnut huolestuttavassa määrin. ${ }^{1}$ Yhtenä onnistuneen ehkäisytyön perusedellytyksenä on niiden syiden mahdollisimman tarkka tunteminen, jotka ajavat epäterveisiin, yhteiskuntaa vahingoittaviin, jopa lainvastaisiinkin tekoihin. Aborttimotiiveja on jo aikaisemmin maassamme tutkittu. ${ }^{2}$ Väestöliiton kansanterveystoimistossa heräsi kuitenkin keväällä 1949 ajatus, että pienikin, vaikkapa vain avioliittoneuvolan kirjẻenvaihtoon perustuva tutkimus voisi tuoda lisävalaistusta kyseiseen suureen ongelmaan.

Gunnar Inghen tutkimus »1125 brev från abortsökande» ${ }^{3}$ on antanut varsinaisen sysäyksen allekirjoittaneelle Helsingin avioliittoneuvolalle saapuneiden kirjeiden tarkempaan tutkimiseen. Omassa maassamme ei tietääkseni kukaan ole julkaissut vastaavanlaista tutkimusta. 
On selvää, että ne johtopäätökset, joihin kirjeiden perusteella tullaan, eivät ole vailla virhemahdollisuuksia, sillä tuloksethan rakentuvat kirjeiden kirjoittajien subjektiiviselle näkemykselle. Mutta toisaalta: kysymyksessä ei ole tutkimus provosoidusta aineistosta eikä se rajoitu vain yhden neuvolan asiakaspiiriin. »Potilaat», joita on kaikkialta maasta, ovat vapaaehtoisesti tarttuneet kynään saadakseen neuvoa ja opastusta monesti sangen kipeään kysymykseensä, miten välttyä raskauden tilasta, jossa ei nähdä muuta mahdollisuutta kuin rikollinen abortti. Kirjeet tuovat varauksetta esiin ne, syyt, joiden perusteella kirjoittajat katsovat olevansa oikeutettuja saamaan neuvontaa syntyvyyden säännöstelyssä.

Aineistoni käsittää 300 valikoimatonta kirjettä, jotka ovat tulleet avioliittoneuvolalle v. $1948-49$.

\section{Kirjeiden lähetysalueet.}

Mainittua aineistoa tarkasteltaessa voidaan havaita, että kirjeet ovat saapuneet melko tasaisesti maamme joka puolelta. Kuitenkin on todettavissa jonkinlaista eroa eri lääneihin nähden. Runsaimmin on kirjeitä tullut Kuopion ja Vaasan lääneistä (n. $15 \%$ ), Turun ja Porin läänistä (n.14 \%) sekä Hämeen ja Oulun lääneistä (n. $12 \%$ ). Uudenmaan läänin osuus on pienin (vain n. $4 \%$ ), mikä johtunee paremmista mahdollisuuksista päästä henkilökohtaisesti käymään Helsingin avioliittoneuvolassa, joka ko. vuosina oli lajissaan ainoa neuvola maassamme. Noin $17 \%$ kirjeistä on tullut kaupungeista ja $83 \%$ maaseudulta. Pohjoisin kirje on saapunut Pelkosenniemeltä. Joutseno on pitäjä, josta on lähetetty kirjeitä eniten $(4 \%)$.

\section{Kirjoittajien ammatti.}

Miehen ammatti on valitettavasti mainittu vain noin kahdessa viidesosassa kaikista kirjeistä. Näistä suurimman ryhmän (n. $40 \%$ ) muodostavat »mieheni on vain tavallinen työmies»-lauseella varustetut. Maanviljelijäväestöä on $\mathrm{n} .30 \%$, virkamiehistöä $\mathrm{n}$. $14 \%$, ammattitaitoista työväestöä n. $12,5 \%$ ja opiskelijoita $3,5 \%$. 
Kirjeen kirjoittaja on tavallisesti vaimo itse (84\%). Naimattomia ei kirjeiden kirjoittajista ole kuin kaksi, toinen heistä useamman vuoden saman miehen kanssa yhdessä asunut, vain »vihkimistä vailla» oleva, toinen taas kihloissa oleva. Mutta onpa perheen pääkin osannut tarttua kynään, kun vaimolta on puuttunut siihen rohkeutta. $14 \%$ kirjeiden kirjoittajista on miehiä. Useimmiten käy kuitenkin ilmi, että tiedustelu on tehty yhteistoiminnassa toisen osapuolen kanssa. $2 \%$ kirjeistä on saapunut hoitavalta lääkäriltä, sukulaiselta tai tuttavalta, jotka ovat olleet huolissaan k.o. äidin terveydentilasta liian tiheään toistuvien raskauksien, perheen taloudellisen ahdinkotilan, miehen juopottelun tms. vuoksi.

\section{Aviopuolisoiden ikä.}

Kaikki ikäluokat ovat edustettuina; nuorin vaimoista on 17, vanhin 43 vuoden ikäinen keskimääräisen iän ollessa 29.7 vuotta. 40 ikävuoden paikkeilla olevia on n. $15 \%$. Miehen ikä käy harvemmin kirjeistä selville, mutta se on 50 kirjeen perusteella keskimäärin 33.6 vuotta; nuorin mies on 22 , vanhin 55 vuoden ikäinen.

\section{Lapsiluku.}

Koska useimmat neuvontaa pyytäessään vetoavat suureen lapsilukuun tai tiheisiin synnytyksiin, on lasten lukumäärä ja ikä selostettu kirjeissä melko tarkkaan. Oheinen taulukko 1, johon vertailun vuoksi on otettu Kaprion ja Rouhunkosken ${ }^{4}$ sekä Siiralan tutkimusten vastaavat tiedot, selvittänee asiaa parhaiten.

Huomiota herättävin eroavuus eri tutkimusten tietojen välillä on $\gg 7$ tai enemmän»-lapsiluvun kohdalla. Kirjeiden kirjoittajista on $15.5 \%$ :lla 7 tai useampia lapsia. Vähintään 10 lasta on yhdeksällä perheellä. $0-1$ lasta on kirjeiden kirjoittajista vain $9.8 \%$ :1la. Avioliittoneuvolan tilastossa vv. 1947-48 (Kaprio ja Rouhunkoski) on vastaava prosenttiluku 16.7 ja Siiralan tilastossa kokonaista 44.9. Syynä näin valtaviin eroihin lienee se, että sekä avioliittoneuvolan että Siiralan tilaston tapauksista suurin osa on pääkau- 
Taulukko 1.

Lasten Oma aineisto

lukumäärä Lukumäärä \%



1

2

3

4

5

6

7 tai enemmän
Kaprio-Rouhunkoski

Lukumäärä \%

$32 \quad 4.5$

$87 \quad 12.2$

$229 \quad 32.1$

$171 \quad 24.0$

$137 \quad 19.2$

$42 \quad 5.9$

$\begin{array}{ll}18 & 2.5\end{array}$

$26 \quad 3.6$

\section{Siirala}

Lukumäärä \%

28

11.5

$81 \quad 33.4$

$64 \quad 26.4$

$33 \quad 13.6$

$\begin{array}{ll}14 & 5.8\end{array}$

$11 \quad 4.5$

$8 \quad 3.3$

$3 \quad 1.2$

Yhteensä $245 \quad 100.0$

$\begin{array}{ll}713 & 100.0\end{array}$

$242 \quad 100.0$

punkilaisia. Väestökeskuksissahan on kautta aikojen ryhdytty syntyvyyden säännöstelyyn pienemmin lapsilukuperustein kuin maaseudulla.

\section{Lasten ikä.}

Seikka, joka myöskin on melko tarkkaan kirjeissä ilmoitettu, on vanhimman ja nuorimman lapsen ikä. Viimeksi mainitustahan selviää suoraan viimeisestä synnytyksestä kulunut aika, eikä ole suinkaan harvinaista, että kirjoittaja vetoaa sen lyhyyteen neuvoja halutessaan. Raskaana on ko. vaimoista ollut 33. Vanhimman lapsen keski-ikä on 6.2 vuotta ja nuorimman $7.8 \mathrm{kk}$. Nuorimman lapsen ikä on vaihdellut seuraavasti:

Taulukko 2.

\begin{tabular}{|c|c|c|c|c|}
\hline \multirow{2}{*}{$\begin{array}{c}\text { Nuorin } \\
\text { lapsi }\end{array}$} & \multicolumn{2}{|c|}{ Oma aineisto } & \multicolumn{2}{|c|}{ Kaprio ja Ruohunkoski } \\
\hline & & $\%$ & & \\
\hline $\begin{array}{l}0-1 \text { v. } \\
1-2,\end{array}$ & $\begin{array}{r}127 \\
38\end{array}$ & $\begin{array}{c}73.4 \\
22.0\end{array}$ & $\begin{array}{l}348 \\
144\end{array}$ & 71.2 \\
\hline $2-3$ & 5 & & 77 & \\
\hline $3-4$, & 1 & 46 & 37 & \\
\hline $4-5$, & 1 & & 17 & 28.8 \\
\hline $5-6$, & 1 & & 38 & \\
\hline & 173 & & 681 & 1000 \\
\hline
\end{tabular}


Valtaosan kirjoittajista muodostavat siis sellaiset, joiden viimeisen lapsen syntymästä ei ole vieläkulunut kahta vuotta. Sama ilmiö siis kuin avioliittoneuvolan tilastossa, mutta vielä selvempänä. Eräässä tapauksessa on nuorimman lapsen iäksi merkitty 1 vrk; tällöin kaksilapsisen perheen isä jo hätääntyneenä tiedustelee, miten voisi ajoissa estää kolmannen maailmaan tulọn yhtä nopeasti edellistä seuraten kuin oli toisen laita; väliä ensimmäisellä ja toisella synnytyksellä oli tässä tapauksessa 1 v. 4 kk.

\section{Avioliiton kesto.}

Melko useissa kirjeissä (121) on selvästi ilmoitettu avioliiton kesto (taulukko 3 ).

Taulukko 3.

$\begin{array}{cc}\text { Avioliiton kesto } & \text { Lukumäärä } \\ 0-1 \text { vuotta } & 3 \\ 1-2 & 8 \\ 2-3 & 20 \\ 3-4 & 21 \\ 4-5 & 18 \\ 5-6 & 8 \\ 6-7 & 5 \\ 7-8 & 7 \\ 8-9 & 4 \\ 9-10 & 4\end{array}$

\begin{tabular}{|c|c|c|}
\hline Avioliito & kesto & Lukumäärä \\
\hline $10-11$ & ruotta & 7 \\
\hline $11-12$ & $\gg$ & 2 \\
\hline $12-13$ & » & 2 \\
\hline $13-14$ & s & 2 \\
\hline $14-15$ & ». & 2 \\
\hline $15-16$ & D & 1 \\
\hline $16-17$ & $\gg$ & 3 \\
\hline $17-18$ & $\gg$ & 1 \\
\hline $21-22$ & 》 & 1 \\
\hline yli 22 & » & 1 \\
\hline
\end{tabular}

Suurimman ryhmän muodostavat, kuten taulukosta selviää, 1-6 vuotta naimisissa olleet, joilla lapsiluku ei siis voi olla varsin korkea. Vaikuttaa siltä, että kysymys on su urimmaksi osaksi melko »nuorista» avioliitoista, joissa osapuolet ovat lähteneet apua hakemaan tiheään toisiaan seuranneiden synnytysten vuoksi, eivätkä niinkään suuren lapsiluvun tähden. 
Aikaisemmin käytetyistä ehkäisymenetelmistä on maininta ainoastaan $13 \%$ :ssa kirjeistä. Yleisin ehkäisymenetelmä on nk. varovaisuus, $51.5 \%$ (39). Ogino-Knausin teoriaa mainitaan noudatetun $18 \%$ :ssa kirjeistä (39); loput (30.5\%) ilmoittavat käyttäneensä useampia erilaisia tapoja kuten huuhteluja, kemiallisia aineita, condomia tai »kaikkia mahdollisia» tiedossaan olevia keinoja. Yleensä tuntuu tietämättömyys ehkäisyvälineiden olemassaoloon nähden olevan sangen suuri. »Olemme tässä asiassa säkissä kasvatettuja.» Tämäntapaiset lauseet toistuvat sangen usein. OginoKnausin teorian suhteen, mikä teoria kyllä tuntuu jollain tavoin olevan yleisessä tietoisuudessa, löytyy mitä ihmeellisimpiä muunnoksia. Ei ole vain yksi ainoa onneton pariskunta, joka kertoo varoneensa eniten juuri ko. teorian varmimpina päivinä ja olleensa sukupuoliyhteydessä ainoastaan oletetun ovulation tienoilla. Useat pyytävät kirjeissään jonkinlaista selvitystä kuukautiskiertoon perustuvasta syntyvyyden säännöstelymahdollisuudesta.

\section{Syyt syntyvyyden säännöstelyyn.}

Kirjeitä tutkiessa saa selvän käsityksen siitä, ettei yksi ainoa syy ole aiheena syntyvyyden säännöstelyneuvontaa pyydettäessä. Melkein poikkeuksetta luettelee kirjoittaja joukon syitä: sosiaalisia (kuten taloudelliset syyt, miehen sairaaloisuudesta, juoppoudesta, asuntosurkeudesta jne. johtuvat), terveydellisiä jopa lääketieteellisiäkin syitä.

Tämän vuoksi on erittäin vaikeata tehdä selvää jaoitusta eri motiiviryhmien kesken. Olen tehnyt alla olevan taulukon (taulukko 4) seuraavan periaatteen mukaan: kustakin kirjeestä on poimittu yksi tai useampia syitä, joita kirjeen kirjoittaja on erityisesti painostanut tai joiden nojalla hän on vedonnut avioliittoneuvolaan apua saadakseen. Näiden $300: n$ kirjeen joukossa on ainoastaan 5 , joissa ei neuvoa kysyttäessä ole vedottu mihinkään erikoiseen syyhyn. 

A. Terveydelliset syyt:
Syy Lukumäärä \%
1. Vaimon sairaus . .................. 22
2. Vaimon yleinen ruumiillinen heikkous 45
3. Vaimo väsynyt, rasittunut, hermostunut 91
4. Edell. synnytys tai raskausajat taval- lista vaikeammat .................. 25
B. Sosiaaliset syyt:
5. Miehen invaliditeetti, sairaus .......... 34
Taloudelliset vaikeudet $\ldots \ldots \ldots \ldots \ldots \ldots . .119$
Vaikeat asunto-olot ....................
Miehen juoppous ................... 13
Miehen opinnot tms.
$2 \quad 5.6$
511.5
23.2
6.4
$\begin{array}{ll}34 & 8.7\end{array}$
$8.7 \quad$
55.4

$\left.\begin{array}{rr}19 & 30.4 \\ 37 & 9.4 \\ 13 & 3.3 \\ 6 & 1.5\end{array}\right\} 44.6$
Yhteensä 392
100.0

Pääpaino terveydellisistä syistä näyttää siis olevan vaimon väsymystilalla. Sosiaalisista syistä näyttelee suurinta osaa vaikeat taloudelliset olot, mihin syyhyn muutenkin kirjeissä yleisimmin vedotaan.

Syiden ja syykombinaatioiden lähempää tarkastelua.

Varsinaisia sairauksia, joita aviovaimojen mainitaan potevan, ovat $\mathrm{mm}$. tuberkuloosi, korkea verenpaine, munuaistauti, struuma, sydämen laajentuma, läppävika jne. Perinnöllisistä sairauksista vaimon puolelta ei ole mainintaa kuin yhdessä kirjeessä, jonka mukaan ao. sairastaa perinnöllistä huonokuuloisuutta. - Miehen sairauksista on huomattavimmalla sijalla raaja-invaliditeetti, jonka aste vaihtelee 20 :stä 80 prosenttiin, mutta myös tuberkuloosia, vatsahaavaa, jopa mielitautejakin esiintyy.

Vaimon väsyneisyys ja rasittuneisuus tuntuu olevan yhteistulos tiheistä synnytyksistä, melko suuresta lapsiluvusta (kuitenkin esiintyy väsyneisyyttä jo kahden, kolmenkin lapsen äideillä) ja taloudellisista vaikeuksista. Näiden lisäksi on vielä sangen usein huoli mahdollisista ristiriidoista avioelämässä liian tiheään tois- 
tuvien synnytysten ja niiden aiheuttaman raskaudenpelon vuoksi. - 4:n lapsen äiti (vanhimman lapsen ikä 3 v., nuorimman $3 \mathrm{kk}$.) kirjoittaa: »Pelko heti uudistuvasta raskaudesta on muodostunut sellaiseksi peikoksi, että se uhkaa tuhota koko elämäniloni ja avio-onnenkin ...». 38-vuotias 10 lapsen äiti selittää: »...kun on vain mökki kalliolla, niin olen ajatellut, että tämä jo riittäisi tähän tilaan, kun ei niitä tahdo ehtiä kunnolla hoitamaankaan. Parempi olisi nämä kymmenen hyvin hoidettua kuin kaksikymmentä huonosti ... avioelämä tahtoo mennä ihan pilalle ...»

Seuraavien lauseiden kirjoittajan olisi varmaan terveellistä tehdä pieni opintomatka tähän »mökkiin kalliolla» (kysymyksessä on 26-vuotias 2 lapsen äiti): »... raskauden pelko on tullut minulle suorastaan painajaisuneksi... minusta tuntuu yksinkertaisesti siltä, etten jaksa kestää tätä jatkuvasti. Minua kauhistuttaa, että minun täytyisi taas ottaa pieni lapsi, juuri kun olen lakannut imettämästä edellistä. Minä en jaksa hoitaa, eikä meillä palkka riitä elämiseen ....»

Seuraava, 33-vuotias 8 lapsen äiti tuntuu olevan myös levoton avio-onnensa suhteen: »... Mistä johtuu sellainen tunne miestäni kohtaan, kun en voi toisin ajoin sietää häntä ollenkaan, tuntuu kuin suorastaan vihaisin häntä, sukupuolielämästä puhumattakaan... Se on aivan kauheata... En tiedä johtuuko se siitä, että meillä on niin paljon lapsia $(8 \mathrm{kpl}$.) ja kun ne ovat syntyneet joka toinen vuosi, lisäksi yhdet kaksoset. Olen yksin saanut kaikki hoitaa. Tänään syntyy lapsi, huomenna täytyy tehdä kaikki yksin, ei ole koskaan ollut ketään, joka olisi ollut hoitamassa». Luulisi, että tällainen äiti - eikä hän suinkaan ole ainoa tämänlaatuinen kirjoittajien joukossa - olisi ansainnut ainakin kodinhoitajan synnytysajaksi kotiinsa.

Monet vaimoista mainitsevat vielä olevansa terveitä, reippaita ja elämänhaluisia, mutta pelkäävät tiheiden synnytysten vuoksi pian menettävänsä ko. ominaisuutensa. Sukulainen on levoton 38-vuotiaan tätinsä puolesta: »Tämä tätini odottaa nyt jouluksi taas uutta vauvaa, yhdestoista järjestyksessä, ja toivoo, että tämän jälkeen saisi edes vähän hengähdysaikaa, lapsia kun on syntynyt 
yksi joka vuosi. Onko nyt pakko rangaista äitiä siksi, että hän on terve ja iloinen, siihen asti kunnes hän nääntyy...»

Sangen usein selviää kirjeistä, että vaimo on ollut tietoinen »niistä keinoista, joiden avulla päästään ei-toivotusta raskaudesta», mutta suhteellisen harva vaikeissakaan olosuhteissa uhkaa kääntyä puoskarin puoleen. Suorastaan liikuttavaa on lukea näitä kirjeitä, joista selviää, millä kauhulla keskellä puutetta ja ahdinkoakin sellaiseen rikoksen mahdollisuuteen suhtaudutaan. 4:n lapsen äiti, jolla synnytykset ovat olleet tiheässä, kirjoittaa: »Olen itse ja myös mieheni jyrkästi sikiönlähdetystä vastaan, joten sitäkään tietä emme lähde apua hakemaan ...» - Koska seuraavassa 10 lasta synnyttäneen äidin kirjeessä erinomaisella tavalla kuvastuu Suomen kansan sitkeimmän ja parhaimman aineksen ominaisuudet, olen halunnut sitä tässä yhteydessä jäljentää pitemmälti: »...Mieheni on vieraassa myllyssä myllärinä, palkka ei riitä, ja pyhän seutuna hän käy häitä soittamassa ja siitä hän sitä rahaa saa, että toimeen tullaan. Mieheni on kunnollinen aviomies ja perheenisä. Hän ei pane rahaa viinaan eikä turhuuteen. Hän on työteliäs ja viisas mies. Meillä suutaroidaan ja räätälöidään, kehrätään ja kudotaan kotona, yhdessä hoidamme lapset parhaan ymmärryksemme mukaan. Mutta minussa on lapsena ollut riisitauti ja lantio jäänyt litteäksi, niin että synnytyk̉set ovat olleet luonnolliset, mutta kovin tuskalliset. Meillä on sellainen vakaumus, että kun raskaus kerran on alkanut, niin ei tule kysymykseenkään raskauden keskeyttäminen. Mutta pyydän nyt neuvoa Teiltä, miten voisin välttyä raskaaksi tulemisesta, vaikka vain 2 vuotta. Sitten kun leipäytyisi, niin vielä vaikka yrittäisi ...»

Melkoista uhrautuvaisuutta osoittaa myöskin seuraava neuvoa pyytävä kirje: »Olen 42-vuotias 7 lapsen äiti. Kolme vuotta sitten minussa todettiin keuhkovika, ja näin ollen jouduin parantolaan. Mennessäni sinne olin lähes kaksi kuukautta raskaana. Olin niin ylirasittunut, että lääkäri ilmoitti, etten voi ruveta toipumaan, ellei raskauttani keskeytetä. Se oli minusta niin suuri rikos, että usein vieläkin sitä itken. Mutta kun kotona odotti suuri perhe, jossa minun paikkani oli tyhjä ja jossa äitiä vielä 
kipeästi tarvittiin, oli minun siihen suostuttava... Lääkäri sanoo, etten jaksaisi enää synnyttää... kieltäytymistä seuraa usein erimielisyyttä, jota emme haluaisi ...»

Kirjoittajien joukossa on myös niitä, jotka vetoavat siihen, että elleivät saa pätevää syntyvyydensäännöstelyn ohjausta, on heidän mahdollisesta ei-toivotusta raskaudesta päästäkseen pakko kääntyä puoskarin puoleen: kahden lapsen äiti (vanhempi 1.5 v., nuorempi $1.5 \mathrm{kk}$.) kirjoittaa: »... mieheni on ollut kaksi kertaa mielisairaana ja Helsingin Lapinlahden sairaalassa hoidettavana ... saa usein raivokohtauksia... Joudun lähtemään yölläkin pakoon vähissä vaatteissa metsään, ja lapset on aina jätettävä sellaisen käsiin... Ellei nytkään tule mitään apua asiaan, niin täytyy lopulta vajota toivottomuuteen ja kääntyä raskauden tullessa sellaisten henkilöiden puoleen, jotka siitä päästävät, vaikka menisi terveys ja lapsilta äiti».

Yleensä saa kirjeistä sen mielikuvan, että mies ja vaimo yhteisvoimin yrittävät ratkaista syntyvyydensäännöstelyprobleemaansa, mutta on myös päinvastaisia tapauksia. 38-vuotias 10 lapsen äiti Uudeltamaalta valittaa: »... mieheni puolelta en saa minkäänlaista ymmärtämystä osakseni. Hän ei suostu käyttämään mitään varmuusvälinettä eikä salli kuulla edes puhuttavankaan nukkumisesta eri huoneissa. Mieheni on minua 17 vuotta vanhempi ja hyvin sairaalloinen... Tiedän, että teen suorastaan rikoksen synnyttäessäni uusia lapsia maailmaan .... - Viiden lapsen äiti on seuraavan seikan vuoksi onneton: »... mieheni ei oikein ymmärrä naisen asemaa ... ja mikä pahinta, hän syyttää aina raskaaksitulosta minua. Onko syy minussa?» - Neljän lapsen äiti (kaikki lapset syntyneet 3:n vuoden sisällä) purkaa mieltään: »Silloin kun ei lasta vielä ole tulossa ja täytyy varoa, hän (mies) on kyllästynyt koko avioliittoon ja lapsiin ja koko elämään yleensä... ja hän on sitten päivät päästään sellainen ärtyinen »lastenelättäjä», eikä onnellinen perheenisä, kuten olla tulisi.»

Puhtaasti taloudellisiin tai asuntosyihin vetoavista tuntuu suhteellisen suuri osa olevan miehiä (37.8 \% kaikista ainoastaan näihin syihin vetoavista). 31-vuotias 3 lapsen isä keski-Suomesta selittää: »... Toivoisimme lapsia vain sen verran, kuin taloudelli- 
nen kantokykymme sallii. Parempi omistaa vähemmän hyvinvoipia ja terveitä lapsia kuin paljon epäterveitä ja vailla riittävää huoltoa.» Ja 33-vuotias kahden lapsen isä Pohjois-Pohjanmaalta: »... olemme varattomia, mutta elämänhaluisia... Vaikka lapsemme ovat meille kaikki kaikessa, emme pariin, kolmeen vuoteen tahtoisi mistään hinnasta lisätä perhettä, kun ei ole edes omaa kotia puhumattakaan muusta ...»

Syiden ja syykombinaatioiden tarkastelua voisi jatkaa vielä pitkältikin, mutta rohkenen olettaa, että edellä esitetyt otteet kirjeistä sekä syitä selvittävä taulukko (taulukko 4) antavat niistä ja niiden ryhmityksestä edes jonkinlaisen yleiskuvan; kuinka totuudenmukaisen, on mahdotonta sanoa, koska vain harva kirje voi antaa objektiivisen näkemyksen asioista.

Edellä selostetut kirjeet todistavat osaltaan, että syntyvyyden säännöstelykysymys on sangen monessa suomalaisessa kodissa kipeä. Ne kuvastavat sitä suurta tietämättömyyttä, joka maassamme vieläkin vallitsee sukupuoliasioihin nähden. Perheenäiti, jonka toinen toistaan tiheään tahtiin seuraavat raskaudet ja synnytykset ovat väsyttäneet, alkaa pelätä omaa miestään. Perheenpää, joka on parhaan ymmärryksensä mukaan yrittänyt olla »varovainen», on vaimonsa toistuvista raskaudentiloista ymmällään ja useinkin työntää syyn asiasta yksin vaimonsa niskoille. Aikoinaan tehdyt yhteiset avioliittosuunnitelmat tuntuvat haihtuvan kuin tuhka tuuleen. Onnellinen nuoripari on vuosien kuluttua toraisa ja riitainen. Lapset joutuvat olemaan vailla kunnollista hoitoa ja huoltoa. Yhteiskunnan sydän, koti, uhkaa ratkeilla liitoksistaan. - Jatkuvaa, tehokasta valistustorimintaa ja apua tarvitaan, ja tuskinpa kukaan epäileekään, etteikö Väestöliiton avioliittoneuvolaverkoston luominen ympäri Suomea olisi ollut paikallaan asian auttamiseksi. Sillä neuvonnalla ja valistustyöllä, jota näiden välityksellä Suomen kodeille pyritään antamaan, ei suinkaan ole tarkoituksena aiheuttaa elämänkielteistä asennetta ja" luoda 1-2-lapsisia perheitä, vaan tarkoituksena on antaa todellista apua siellä, missä sitä tarvitaan, ja luomalla turvallisuu- 
den tunnetta aviopuolisoiden keskinäisiin suhteisiin lujittaa sitä rohkeata tulevaisuudenuskoa, joka Suomen kansalla kautta aikojen on ollut.

\section{Lähdeviitteitä.}

1 Pitkänen, Heikki, Människa och Miljö 1947: 235.

2 Siirala, Martti, Duodecim 1936: 858. - Timonen, Sakari, Suomen Lääkärilehti 1949: 101. - Reenkola, Mies, Annales chirurgiae et gynaekologiae Fenniae 1949: 38: Suppl. 3: 429.

3 Statens offentliga utredningar 1944: 51, Bilaga 5: 301.

4 Annales chirurgiae et gynaecologiae Fenniae 1949: 38: Suppl. 3: 224. 